\title{
Comparative efficacy and safety of biosimilar infliximab and other biological treatments in ankylosing spondylitis: systematic literature review and meta-analysis
}

\author{
Petra Baji • Márta Péntek • Sándor Szántó • \\ Pál Géher · László Gulácsi · Orsolya Balogh • \\ Valentin Brodszky
}

Received: 4 February 2014/ Accepted: 31 March 2014/Published online: 16 May 2014

(C) Springer-Verlag Berlin Heidelberg 2014

\begin{abstract}
Objectives To compare the efficacy and safety of infliximab-biosimilar with other biological drugs for the treatment of active ankylosing spondylitis (AS).

Methods Systematic literature review for randomized controlled trials (RCTs) with adalimumab, etanercept, golimumab, infliximab and infliximab-biosimilar in AS was performed and indirect meta-analysis (Bayesian mixed treatment comparison) was carried out. The proportion of patients reaching $20 \%$ improvement by the assessment of Spondyloarthritis International Society response criteria (ASAS20) at weeks 12 and 24 was used as efficacy endpoints, and the occurrence of serious adverse events at week 24 was applied to compare the safety of the biologicals.

Results Altogether, 13 RCTs, identified by the systematic literature search, were included in the analysis. Results on the ASAS20 efficacy endpoint were reported for week 12 in 12 RCTs involving 2,395 patients, and for week 24 in 5 RCTs comprising 1,337 patients. All the five biological
\end{abstract}

P. Baji ( $₫)$ · M. Péntek · L. Gulácsi · O. Balogh · V. Brodszky Department of Health Economics, Corvinus University of Budapest, Fővám tér 8, 1093 Budapest, Hungary

e-mail: petra.baji@uni-corvinus.hu

M. Péntek

Department of Rheumatology, Flór Ferenc County Hospital, Semmelweis tér 1, 2143 Kistarcsa, Hungary

S. Szántó

Division of Rheumatology, Institute of Medicine, University of Debrecen Medical and Health Sciences Center, Nagyerdei krt 98, 4032 Debrecen, Hungary

P. Géher

No. I. Department of Rheumatology, Budai Irgalmasrendi Hospital, Frankel Leó út 54, 1023 Budapest, Hungary agents proved to be significantly superior to placebo. Infliximab showed the highest odds ratio (OR) of $7.2(95 \%$ CI 3.68-13.19) compared to placebo, followed by infliximab-biosimilar with OR 6.25 (95 \% CI 2.55-13.14), both assessed at week 24. No significant difference was found between infliximab-biosimilar and other biological treatments regarding their efficacy and safety.

Conclusions This is the first study which includes a biosimilar drug in the meta-analysis of biological treatments in AS. The results have proven the similar efficacy and safety profile of infliximab-biosimilar treatment compared to other biologicals.

Keywords Ankylosing spondylitis - Biological drug · Biosimilar pharmaceuticals · Meta-analysis · Efficacy . Safety

JEL Classification I10 $\cdot$ I19

\section{Introduction}

So far adalimumab, etanercept, golimumab and infliximab have been approved by the European Medicine Agency (EMA) for the treatment of adults with severe, active ankylosing spondylitis (AS) who have responded inadequately to conventional therapy (see detailed description of the disease in Péntek et al. [1] in this Supplement).

In September 2013, the first biosimilar therapy, namely infliximab-biosimilar (CT-P13, trade names: Remsima and Inflectra) was licensed in the EU for the treatment of AS. The results of a Phase 1 , multicenter, double-blind randomized controlled trial (RCT) with infliximab-biosimilar (called the PLANETAS study) were published in May, 2013 [2]. The trial was designed to demonstrate pharmacokinetic 
equivalence and efficacy and safety comparability of infliximab-biosimilar (CT-P13) and the originator infliximab in active AS patients. The RCT was conducted at 46 sites across 10 countries in Europe, Asia and Latin America between November, 2010 and December, 2011. Altogether, 250 patients were enrolled in the study. Besides pharmacokinetics, the proportions of patients achieving 20 and $40 \%$ improvement according to the assessment of Spondyloarthritis International Society ${ }^{1}$ response criteria (ASAS20 and ASAS40) at weeks 14 and 30 were the endpoints to assess efficacy [3]. (See the definition of ASAS response criteria in the Methods Section). No significant differences were found in the efficacy and safety of the originator infliximab and infliximab-biosimilar. According to the study results, ASAS20 and ASAS40 responses at week 30 were 70.5 and $51.8 \%$ for infliximab-biosimilar and 72.4 and $47.4 \%$ for originator infliximab, respectively. The authors concluded that pharmacokinetic, efficacy and safety profiles of the infliximab-biosimilar and the originator infliximab were equivalent in patients with active AS [2].

According to our knowledge, no meta-analyses have been published yet in AS, which compare the efficacy and safety of the infliximab-biosimilar treatment to the other biological drugs indicated in AS. Thus, the aim of this study was to carry out a systematic literature review and meta-analysis of published RCTs in order to compare the efficacy and safety of infliximab-biosimilar to adalimumab, etanercept, golimumab and infliximab in $\mathrm{AS}^{2}$

Besides the PLANETAS trial, no other RCTs, presenting head-to-head comparison of biologicals, have been published yet in this diagnosis [4]. Due to the difference in comparators across the trials (infliximab-biosimilar is compared to infliximab in the PLANETAS study, while other biologicals are compared to placebo), traditional methods cannot be applied for the comparison. Therefore, we used an indirect comparison method, namely mixed treatment comparison (MTC) to evaluate the efficacy and safety of biological treatments. MTC permits indirect comparisons between study drugs with different comparators as well $[5,6]$.

\section{Methods}

Treatments

In the current analysis adalimumab, etanercept, golimumab and infliximab are considered as comparators of

\footnotetext{
${ }^{1}$ Former Asessment in Ankylosing Spondylitis.

2 The search dates were November 1, 2009 to August 20, 2013. Certolizumab pegol was registered for the treatment of AS on 19 September 2013, thus it was not included in our analysis.
}

infliximab-biosimilar as these biologicals are recommended by the EMA for the treatment of AS. Only doses recommended by the EMA were considered in the analysis: adalimumab (40 mg every other week as a subcutaneous injection); etanercept ( $25 \mathrm{mg}$ twice weekly, or $50 \mathrm{mg}$ once weekly as a subcutaneous injection); golimumab (50 mg once a month as a subcutaneous injection); infliximab $(5 \mathrm{mg} / \mathrm{kg}$ at $0,2,6$ weeks and then every $6-8$ weeks as intravenous infusions over a 2 -h period) and infliximabbiosimilar (CT-P13) $(5 \mathrm{mg} / \mathrm{kg}$ at $0,2,6$ weeks and then every 6-8 weeks as intravenous infusions over a 2-h period).

\section{Literature search}

Electronic databases (Medline and Cochrane Library) as well as references of retrieved articles were searched. The Cochrane highly sensitive search strategy [7] was applied to identify randomized controlled publications and was combined with the disease (ankylosing spondylitis, ankylosing spondyloarthritis, spondyloarthritide) and drug names for adalimumab, etanercept, golimumab and infliximab. ${ }^{3}$ We carried out the search for the period between November 1, 2005 and August 20, 2013. To identify RCTs from earlier years, we relied on the systematic review of McLeod et al. [8] published in 2007, which assessed the comparative clinical effectiveness of adalimumab, etanercept and infliximab for the treatment of AS. A separate search was carried out to identify RCTs with the biosimilar agent, using its generic name (CT-P13) as search term, and in this case no further restrictions were applied.

\section{Exclusion and inclusion criteria}

Double-blind RCTs in AS with parallel design, with full paper obtainable were included. Non randomized or uncontrolled studies, observational studies, case series, letters to editor, studies with no abstracts or with conference abstracts only were not included. A further inclusion criterion was that AS patients, diagnosed based on the modified New York criteria [9], in at least one arm of the trial must receive adalimumab, etanercept, golimumab, infliximab or infliximab-biosimilar treatment at the labelled dose. Studies which examined only off-label doses, or other than the suggested administration (e.g. infliximab combined with

\footnotetext{
3 ("Ankylosing spondylitis" OR "ankylosing spondyloarthritis" OR "spondyloarthritide") AND ("adalimumab" OR "infliximab" OR "golimumab" OR "etanercept") AND [(randomized controlled trial[pt] OR controlled clinical trial[pt] OR randomized[tiab] OR placebo[tiab] OR "clinical trials as topic"[MeSH Terms] OR randomly[tiab] OR trial[ti]) NOT ("animals"[MeSH Terms] NOT "humans"[MeSH Terms])] AND ("2005/11/01”[PDAT]: “2013/08/ 20"[PDAT]).
} 
methotrexate) studies reporting solely on laboratory measures aimed at investigating disease, or treatment mechanisms and which do not report relevant clinical outcomes were excluded. Studies involving patients younger than 18 years were also excluded, as well as pilot studies.

\section{Data extraction}

We used the same data extraction process and quality assessment of the RCTs as in our previous study in which we assessed the efficacy and safety of infliximab-biosimilar in another inflammatory rheumatic disease, rheumatoid arthritis (RA). Details have been published elsewhere [10]. In brief, data on study design, patients' demographic and morbidity characteristics, treatment interventions, endpoints and duration of follow-up were subtracted. The quality of selected studies was evaluated using the JADAD-score [11].

\section{Endpoints}

The proportions of patients with ASAS20 response at weeks 12 and 24 were used as efficacy endpoints in the meta-analysis of AS trials. The ASAS20 improvement criteria requires improvement of $\geq 20 \%$ and $\geq 1$ unit in at least 3 of 4 well-defined specific domains (patient global assessment, pain, function and inflammation) on a scale of 10 and no worsening of $\geq 20 \%$ and $\geq 1$ in remaining domain on a scale of 10 [3]. To evaluate the safety of biological therapies, the occurrence of serious adverse events at week 24 was used as a safety endpoint in the analysis. We could not carry out the safety analysis at week 12 , as the infliximab-biosimilar study presented safety results only at week 30 [2].

\section{Meta-analysis}

Mixed treatment comparison (MTC) was applied in the analysis $[5,6]$. We estimated the posterior densities for all unknown parameters using MCMC (Markov chain Monte Carlo) for each model in WinBUGS version 1.4.3 (MRC Biostatistics Unit, Cambridge, UK). We applied a random effects model to estimate the odds ratios (OR) as the measure of relative treatment effect. We also present the $95 \%$ credibility intervals $(\mathrm{CI})$ which contain the true value of OR with $95 \%$ probability.

\section{Results}

Literature review

Our literature search for the period between November 1, 2005 and August 20, 2013 yielded 336 potential citations for RCTs. Among them seven RCTs in AS with the target drugs of our study were identified. Five of them met our inclusion criteria [12-16]. One study was not enrolled as it examined off-label infliximab therapy $(3 \mathrm{mg} / \mathrm{kg}$ ) [17]. To have comparable results, one study was excluded as infliximab was given in combination with methotrexate [18]. Till November 2005, nine RCTs identified by the systematic review of McLeod et al. [8] were screened for eligibility. Seven of them met our enrollment criteria, and were included in the current meta-analysis [19-25]. (One study [26] was excluded as it examined the effect of etanercept at week 6 , and another study was published later in a scientific journal by van der Heijde et al. [13], which was identified by our search as well in the Medline database). The search for infliximab-biosimilar did not identify any other RCT than the PLANETAS trial [2].

Thus, altogether 13 studies were included in the metaanalysis. Eight of them were 12-week trials: one with infliximab [24], five with etanercept [13-15, 21, 22] and two with adalimumab [12, 20]. Five of 13 studies were at least 24-week trials: one with infliximab [25], one with adalimumab [19], one with etanercept [23], one with golimumab [16] and one with infliximab-biosimilar [2].

The main characteristics of the RCTs, i.e. the number of patients enrolled, the treatment arms and the JADADscores are presented in Table 1.

Mixed treatment comparison meta-analysis: efficacy and safety

\section{Efficacy}

The infliximab-biosimilar study and Inman et al. [16] golimumab study presented ASAS20 results at week 14, and the Gorman et al. [21] etanercept study at week 16 (4 months). These studies were pooled with trials presenting results for week 12. In this way, results of twelve studies involving 2,395 patients were analyzed for ASAS20 endpoint at week 12. All biologicals were found to be significantly superior to placebo. Compared to placebo, infliximab showed the highest OR for ASAS20 response at week 12, OR 6.74 (3.81-11.3), followed by infliximab-biosimilar OR 6.39 (2.75-12.78) and golimumab OR 5.7 (2.88-10.44). Results are presented in Table 2.

Four studies reported ASAS20 response at week 24. The infliximab-biosimilar RCT presented ASAS20 results at week 30. However, patients in this trial received the same number of infusions as patients in the 24-week infliximab study. Therefore, we pooled these five studies involving 1,337 patients in the analysis of ASAS20 response at week 24.

At week 24, infliximab showed the highest ORs compared to placebo [OR 7.2 (95\% CI 3.68-13.19)], followed by infliximab-biosimilar [OR 6.25 [95\% CI 2.55-13.14)] 


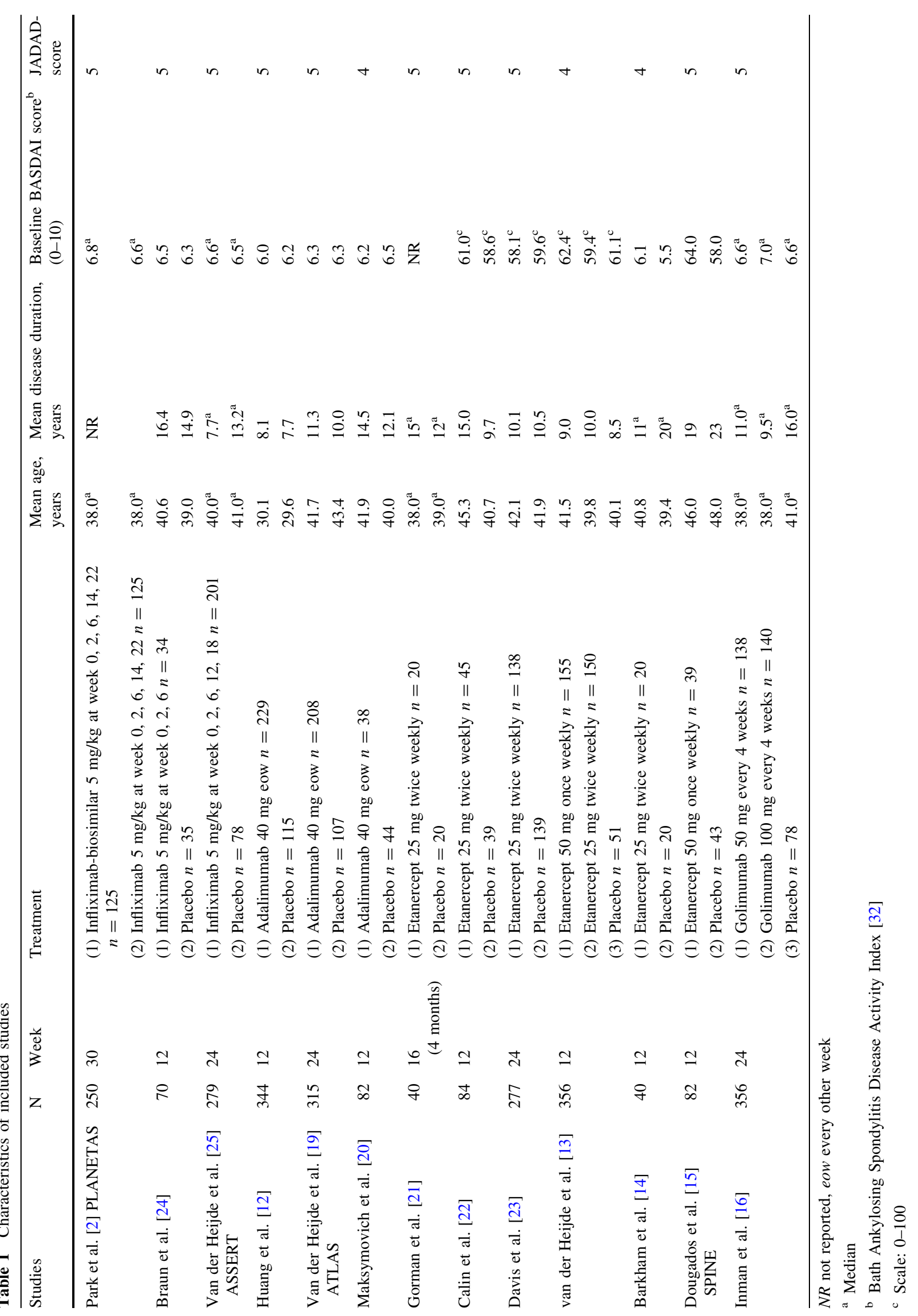


Table 2 The efficacy of infliximab-biosimilar and other biologicals compared to placebo in $\mathrm{AS}$, results of the mixed treatment comparison

${ }^{a}$ Results for weeks 14 and 30 were available and considered for infliximab-biosimilar

\begin{tabular}{lccl}
\hline Substance & $\begin{array}{l}\text { ASAS20 at week 12, } \\
\text { OR }(95 \% \text { CI })\end{array}$ & $\begin{array}{l}\text { ASAS20 at week 24, } \\
\text { OR }(95 \% \text { CI })\end{array}$ & $\begin{array}{l}\text { Serious adverse events } \\
\text { OR }(95 \% \text { CI })\end{array}$ \\
\hline Adalimumab & $4.65(3.29-6.43)$ & $4.81(2.67-8.18)$ & $1.57(0.27-5.72)$ \\
Etanercept & $4.35(3.09-5.96)$ & $4.76(2.73-7.81)$ & $2.36(0.64-6.58)$ \\
Golimumab & $5.7(2.88-10.44)$ & $4.53(2.32-8.22)$ & $0.69(0.14-2.1)$ \\
Infliximab & $6.74(3.81-11.3)$ & $7.2(3.68-13.19)$ & $2.71(0.35-12.03)$ \\
Infliximab-biosimilar $^{\mathrm{a}}$ & $6.39(2.75-12.78)$ & $6.25(2.55-13.14)$ & $2.31(0.17-11.43)$
\end{tabular}

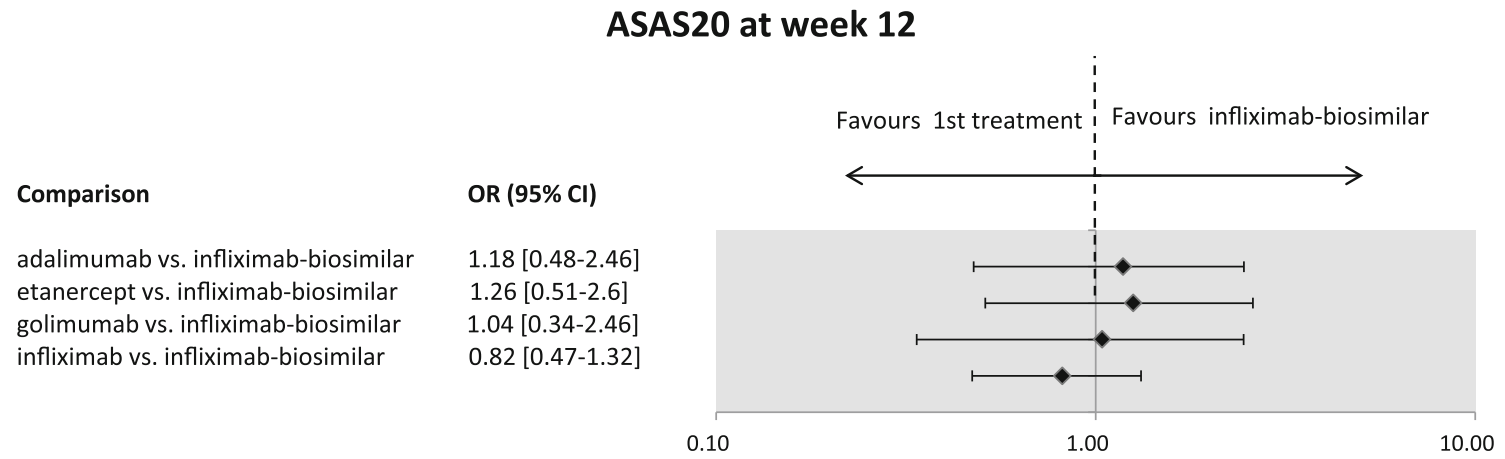

ASAS20 at week 24

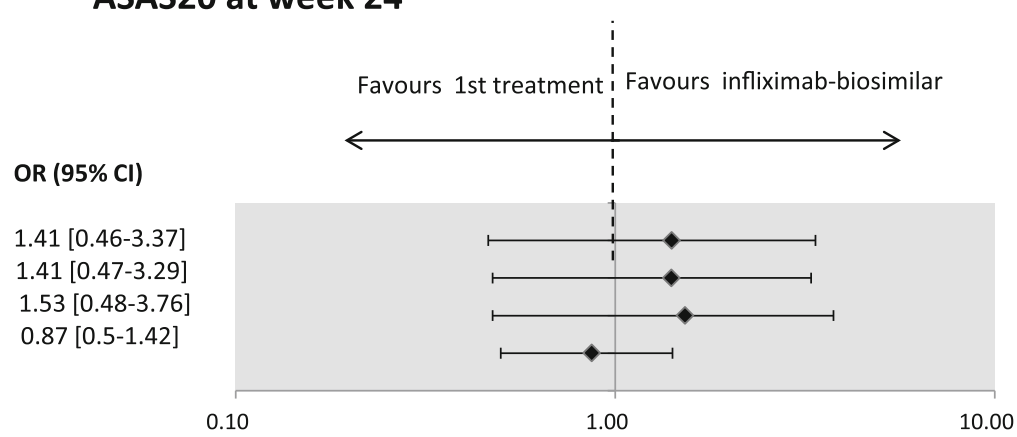

necessarily statistically significantly more effective) compared to the originator biologicals. Credibility intervals provide information on whether the difference between treatments is statistically significant. If the CI contains the value 1 , the difference is not statistically significant

endpoint the lower ORs are in favor of biologicals, as the lower the OR, the lower the chance of the occurrence of serious AEs compared to placebo.

Golimumab gave the lowest ORs compared to placebo [OR 0.69 (95\% CI 0.14-2.1)], followed by adalimumab [OR 1.57 (95\% CI 0.27-5.72)] and infliximab-biosimilar [OR 2.31 (95\% CI 0.17-11.43)]. We have not found significant difference between placebo and biological treatments regarding safety.

Regarding the pairwise comparison of the treatments, we found no significant difference in the safety of infliximab-biosimilar and other biological treatments (see Fig. 2). 


\section{Comparison}

adalimumab vs. infliximab-biosimilar etanercept vs. infliximab-biosimilar golimumab vs. infliximab-biosimilar infliximab vs. infliximab-biosimilar

\section{Serious AE}

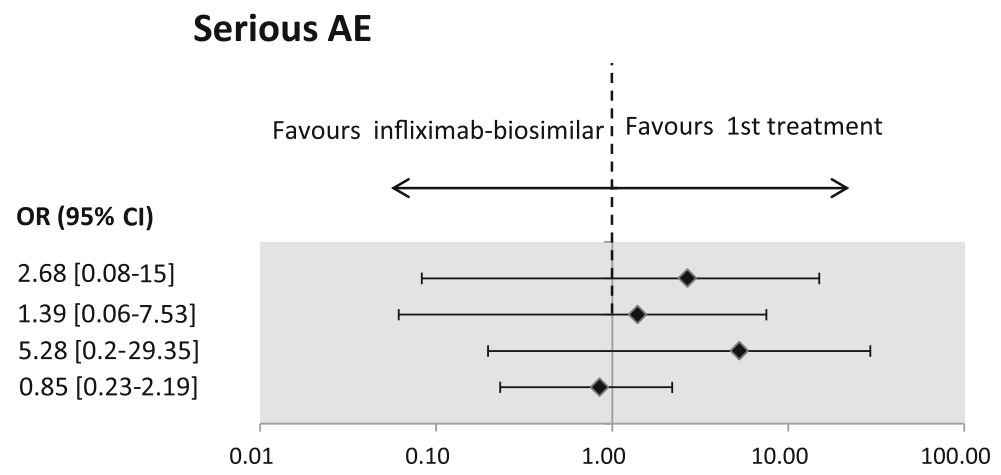

biosimilar treatment is safer (although not necessarily statistically significantly safer). Credibility intervals provide information on whether the difference between treatments is statistically significant. If the CI contains the value 1 , the difference is not statistically significant

Nevertheless, authors came to the same conclusion as us, namely that infliximab $5 \mathrm{mg} / \mathrm{kg}$ at $0,2,6$ weeks was the best efficacious therapy [OR 6.53 (95\% CI 3.35, 11.61)] compared to placebo [31]. No significant differences were found between the biological treatments either.

Migliore et al. [4] compared ASAS20 response at week 24 between biological agents. Three RCTs were included in their analysis, as the 24-week golimumab RCT and the recently published RCT with infliximab-biosimilar were not included [4]. The authors found no significant differences when comparing directly one biological agent against another. When compared with placebo, infliximab increased the probability of response by 7 times (OR 6.8), adalimumab by 4 times (OR 4.4), and etanercept by 5 times (OR 4.9). These results are in line with our findings, and confirm the validity of our study.

We have to acknowledge some limitations of our study. First, a potential weakness of this meta-analysis arises from the fact that the trials from which data are combined are likely to differ in their design. For example, the infliximabbiosimilar study reports efficacy and safety results at week 14 and 30 while most of the others do so for week 12 and 24; that is infliximab-biosimilar results are from 2 to 6 weeks later, respectively. However, we do not expect strong bias related to this difference as patients in the infliximab-biosimilar study received the same number of infusions as patients in the infliximab study. Also, patient characteristics (age, disease duration, baseline BASDAI score) varied slightly across studies. Furthermore, only the primary efficacy outcome was assessed in this analysis (ASAS20). Other efficacy endpoints were not investigated as, on the one hand, some of the RCTs have not reported ASAS40, and on the other hand, the infliximab-biosimilar RCT did not assess another activity score, the $50 \%$ improvement of the initial disease activity score of the Bath ankylosing spondylitis disease activity index (BASDAI50). Also, the safety analysis was carried out only for 
the occurrence of serious adverse events at week 24 , since the infliximab-biosimilar study presented safety results only at week 30 . In this way only five RCTs were included in the safety analysis. Despite these limitations, we believe that our analysis contributes with important results to the evidence-based health care evaluation of AS that might support clinical as well as financial decision making.

In conclusion, infliximab-biosimilar has recently been approved by the European Medicines Agency for the treatment of adults with active AS and this first metaanalysis suggests that it is similar in both efficacy and safety to other biologicals. Further head-to-head comparisons, continuous data collection and benefit-risk assessment might confirm our results.

Acknowledgments The study was supported by an unrestricted grant from EGIS Pharmaceuticals and the Center for Public Affairs Studies Foundation.

\section{References}

1. Péntek, M., Poór, Gy., Wiland, P., Martina, O., Brzosko, M., Codrenau, C., Brodszky, N., Gulácsi, L.: Biologic therapy in inflammatory rheumatic diseases: issues in Central and Eastern European countries. Eur. J. Health Econ. (2014). doi:10.1007/ s10198-014-0592-6

2. Park, W., Hrycaj, P., Jeka, S., Kovalenko, V., Lysenko, G., Miranda, P., Mikazane, H., Gutierrez-Urena, S., Lim, M., Lee, Y.A., Lee, S.J., Kim, H., Yoo, D.H., Braun, J.: A randomised, doubleblind, multicentre, parallel-group, prospective study comparing the pharmacokinetics, safety, and efficacy of CT-P13 and innovator infliximab in patients with ankylosing spondylitis: the PLANETAS study. Ann. Rheum. Dis. 72(10), 1605-1612 (2013)

3. Sieper, J., Rudwaleit, M., Baraliakos, X., Brandt, J., Braun, J., Burgos-Vargas, R., Dougados, M., Hermann, K.G., Landewe, R., Maksymowych, W., van der Heijde, D.: The Assessment of SpondyloArthritis international Society (ASAS) handbook: a guide to assess spondyloarthritis. Ann. Rheum. Dis. 68(Suppl 2), ii1-ii44 (2009)

4. Migliore, A., Broccoli, S., Bizzi, E., Lagana, B.: Indirect comparison of the effects of anti-TNF biological agents in patients with ankylosing spondylitis by means of a mixed treatment comparison performed on efficacy data from published randomised, controlled trials. J. Med. Econ. 15(3), 473-480 (2012)

5. Ades, A.E., Sculpher, M., Sutton, A., Abrams, K., Cooper, N., Welton, N., Lu, G.: Bayesian methods for evidence synthesis in cost-effectiveness analysis. Pharmacoeconomics 24(1), 1-19 (2006)

6. Lu, G., Ades, A.E.: Combination of direct and indirect evidence in mixed treatment comparisons. Stat. Med. 23(20), 3105-3124 (2004)

7. Higgins, J.P.T., Green, S.: Cochrane handbook for systematic reviews of interventions version 5.0.2 [updated September 2009]. The Cochrane Collaboration (2009)

8. McLeod, C., Bagust, A., Boland, A., Dagenais, P., Dickson, R., Dundar, Y., Hill, R.A., Jones, A., Mujica Mota, R., Walley, T.: Adalimumab, etanercept and infliximab for the treatment of ankylosing spondylitis: a systematic review and economic evaluation. Health Technol. Assess. 11(28), 1-158 (iii-iv) (2007)

9. van der Linden, S., Valkenburg, H.A., Cats, A.: Evaluation of diagnostic criteria for ankylosing spondylitis. A proposal for modification of the New York criteria. Arthritis Rheum. 27(4), 361-368 (1984)

10. Baji, P., Péntek, M., Czirják, L., Szekanecz, Z., Nagy, Gy., Gulácsi, L., Brodszky, V.: Efficacy and safety of infliximabbiosimilar compared to other biological drugs in rheumatoid arthritis; a mixed treatment comparison. Eur. J. Health Econ. Suppl. (2014). doi:10.1007/s10198-014-0594-4

11. Jadad, A.R., Moore, R.A., Carroll, D., Jenkinson, C., Reynolds, D.J., Gavaghan, D.J., McQuay, H.J.: Assessing the quality of reports of randomized clinical trials: is blinding necessary? Control. Clin. Trials 17(1), 1-12 (1996)

12. Huang, F., Gu, J., Zhu, P., Bao, C., Xu, J., Xu, H., Wu, H., Wang, G., Shi, Q., Andhivarothai, N., Anderson, J., Pangan, A.L.: Efficacy and safety of adalimumab in Chinese adults with active ankylosing spondylitis: results of a randomised, controlled trial. Ann. Rheum. Dis. 73(3), 587-594 (2014)

13. van der Heijde, D., Da Silva, J.C., Dougados, M., Geher, P., van der Horst-Bruinsma, I., Juanola, X., Olivieri, I., Raeman, F., Settas, L., Sieper, J., Szechinski, J., Walker, D., Boussuge, M.P., Wajdula, J.S., Paolozzi, L., Fatenejad, S.: Etanercept $50 \mathrm{mg}$ once weekly is as effective as $25 \mathrm{mg}$ twice weekly in patients with ankylosing spondylitis. Ann. Rheum. Dis. 65(12), 1572-1577 (2006)

14. Barkham, N., Coates, L.C., Keen, H., Hensor, E., Fraser, A., Redmond, A., Cawkwell, L., Emery, P.: Double-blind placebo-controlled trial of etanercept in the prevention of work disability in ankylosing spondylitis. Ann. Rheum. Dis. 69(11), 1926-1928 (2010)

15. Dougados, M., Braun, J., Szanto, S., Combe, B., Elbaz, M., Geher, P., Thabut, G., Leblanc, V., Logeart, I.: Efficacy of etanercept on rheumatic signs and pulmonary function tests in advanced ankylosing spondylitis: results of a randomised double-blind placebo-controlled study (SPINE). Ann. Rheum. Dis. 70(5), 799-804 (2011)

16. Inman, R.D., Davis Jr, J.C., Heijde, D., Diekman, L., Sieper, J., Kim, S.I., Mack, M., Han, J., Visvanathan, S., Xu, Z., Hsu, B., Beutler, A., Braun, J.: Efficacy and safety of golimumab in patients with ankylosing spondylitis: results of a randomized, double-blind, placebo-controlled, phase III trial. Arthritis Rheum. 58(11), 3402-3412 (2008)

17. Inman, R.D., Maksymowych, W.P.: A double-blind, placebocontrolled trial of low dose infliximab in ankylosing spondylitis. J. Rheumatol. 37(6), 1203-1210 (2010)

18. Marzo-Ortega, H., McGonagle, D., Jarrett, S., Haugeberg, G., Hensor, E., O'Connor, P., Tan, A.L., Conaghan, P.G., Greenstein, A., Emery, P.: Infliximab in combination with methotrexate in active ankylosing spondylitis: a clinical and imaging study. Ann. Rheum. Dis. 64(11), 1568-1575 (2005)

19. van der Heijde, D., Kivitz, A., Schiff, M.H., Sieper, J., Dijkmans, B.A., Braun, J., Dougados, M., Reveille, J.D., Wong, R.L., Kupper, H., Davis Jr, J.C.: Efficacy and safety of adalimumab in patients with ankylosing spondylitis: results of a multicenter, randomized, double-blind, placebo-controlled trial. Arthritis Rheum. 54(7), 2136-2146 (2006)

20. Maksymowych, W., Rahman, P., Keystone, E., Wong, R.L., Inman, R.: Efficacy of adalimumab in active ankylosing spondylitis (AS) - results of the Canadian AS study. Arthritis Rheum. 52, 505 (2005)

21. Gorman, J.D., Sack, K.E., Davis Jr, J.C.: Treatment of ankylosing spondylitis by inhibition of tumor necrosis factor alpha. N. Engl. J. Med. 346(18), 1349-1356 (2002)

22. Calin, A., Dijkmans, B.A., Emery, P., Hakala, M., Kalden, J., Leirisalo-Repo, M., Mola, E.M., Salvarani, C., Sanmarti, R., Sany, J., Sibilia, J., Sieper, J., van der Linden, S., Veys, E., Appel, A.M., Fatenejad, S.: Outcomes of a multicentre randomised clinical trial of etanercept to treat ankylosing spondylitis. Ann. Rheum. Dis. 63(12), 1594-1600 (2004) 
23. Davis Jr, J.C., Van Der Heijde, D., Braun, J., Dougados, M., Cush, J., Clegg, D.O., Kivitz, A., Fleischmann, R., Inman, R., Tsuji, W.: Recombinant human tumor necrosis factor receptor (etanercept) for treating ankylosing spondylitis: a randomized, controlled trial. Arthritis Rheum. 48(11), 3230-3236 (2003)

24. Braun, J., Brandt, J., Listing, J., Zink, A., Alten, R., Golder, W., Gromnica-Ihle, E., Kellner, H., Krause, A., Schneider, M., Sorensen, H., Zeidler, H., Thriene, W., Sieper, J.: Treatment of active ankylosing spondylitis with infliximab: a randomised controlled multicentre trial. Lancet 359(9313), 1187-1193 (2002)

25. van der Heijde, D., Dijkmans, B., Geusens, P., Sieper, J., DeWoody, K., Williamson, P., Braun, J.: Efficacy and safety of infliximab in patients with ankylosing spondylitis: results of a randomized, placebo-controlled trial (ASSERT). Arthritis Rheum. 52(2), 582-591 (2005)

26. Brandt, J., Khariouzov, A., Listing, J., Haibel, H., Sorensen, H., Grassnickel, L., Rudwaleit, M., Sieper, J., Braun, J.: Six-month results of a double-blind, placebo-controlled trial of etanercept treatment in patients with active ankylosing spondylitis. Arthritis Rheum. 48(6), 1667-1675 (2003)

27. Boyce, E.G., Halilovic, J., Stan-Ugbene, O.: Golimumab: review of the efficacy and tolerability of a recently approved tumor necrosis factor-alpha inhibitor. Clin. Ther. 32(10), 1681-1703 (2010)

28. Poddubnyy, D., Rudwaleit, M.: Efficacy and safety of adalimumab treatment in patients with rheumatoid arthritis, ankylosing spondylitis and psoriatic arthritis. Expert Opin. Drug Saf. 10(4), 655-673 (2011)
29. Li, Z.H., Zhang, Y., Wang, J., Shi, Z.J.: Etanercept in the treatment of ankylosing spondylitis: a meta-analysis of randomized, double-blind, placebo-controlled clinical trials, and the comparison of the Caucasian and Chinese population. Eur. J. Orthop. Surg. Traumatol. 23(5), 497-506 (2013)

30. Thaler, K.J., Gartlehner, G., Kien, C., Van Noord, M.G., Thakurta, S., Wines, R.C.M., Hansen, R.A., McDonagh, M.S.: Drug class review: targeted immune modulators: final update 3 report [Internet]. http://pharmacy.oregonstate.edu/drug_policy/sites/ default/files/pages/dur_board/reviews/articles/2012_06_28_ TIMS_executive.pdf (2012)

31. Shu, T., Chen, G.H., Rong, L., Feng, F., Yang, B., Chen, R., Wang, J.: Indirect comparison of anti-TNF-alpha agents for active ankylosing spondylitis: mixed treatment comparison of randomized controlled trials. Clin. Exp. Rheumatol. 31(5), 717-722 (2013)

32. Zochling, J.: Measures of symptoms and disease status in ankylosing spondylitis: ankylosing Spondylitis Disease Activity Score (ASDAS), Ankylosing Spondylitis Quality of Life Scale (ASQoL), Bath Ankylosing Spondylitis Disease Activity Index (BASDAI), Bath Ankylosing Spondylitis Functional Index (BASFI), Bath Ankylosing Spondylitis Global Score (BAS-G), Bath Ankylosing Spondylitis Metrology Index (BASMI), Dougados Functional Index (DFI), and Health Assessment Questionnaire for the Spondylarthropathies (HAQ-S). Arthritis Care Res (Hoboken) 63(Suppl 11), S47-S58 (2011) 